Revista Docência do Ensino

Superior

v. 1,2011

\title{
APRIMORAMENTO E ATUALIZAÇÃO DOS MATERIAIS DA DISCIPLINA DE BROMATOLOGIA
}

\section{UPDATE OF BROMATOLOGY COURSE}

Hugo Colombarolli Bonfa
UFMG

Carlos Renato Viegas

UFMG

Antonio Carlos Ramos dos Santos UFMG

Raphael Nogueira Bahiense UFMG

Daniel Emygdio de Faria Filho UFMG

Luciana Castro Geraseev

UFMG

\section{RESUMO}

As atividades do Programa Especial de Graduação na área de Bromatologia objetivaram confeccionar um mostruário de alimentos e um herbário de plantas do cerrado. Através do mostruário, foi apresentado aos alunos alimentos e componentes utilizados pelas indústrias produtoras de ração animal e, através do herbário, foram disponibilizadas exsicatas de plantas nativas e tradicionais de interesse forrageiro. A confecção do mostruário e do herbário despertou grande interesse nos alunos e contribuiu para a conscientização da importância do desenvolvimento de uma agropecuária baseada na sustentabilidade e no conhecimento da realidade das populações locais. Além do mostruário e do herbário, foram desenvolvidas atividades visando melhorar a disponibilização de material didático para consulta dos discentes, sendo reestruturada uma "Apostila Teórica" e confeccionada uma "Apostila de Práticas", que melhoraram a dinâmica da aula e proporcionaram maior embasamento aos alunos para futuras disciplinas como Nutrição de Ruminantes e Nutrição de Não Ruminantes.

Palavras-Chave: Bromatologia. Material Didático. Nutrição Animal.

\section{ABSTRACT}

The activities of the Programa Especial de Graduação in Bromatology area aimed to make a showcase of foods and a herbarium of plants from Cerrado. Through the showcase of foods was presented to the students components used for producing animal feed industries, and were available through the herbarium specimens of native and traditional plants used as forage. The showcase and herbarium aroused great interest among students and contributed to the awareness of the importance of developing an agriculture based on sustainability and its knowledge of local populations. In addition, were restructured a "Theoretical Workbook" and made a "Practice Workbook, which improved the dynamics of class and provide to students a better foundation for future disciplines as Ruminant Nutrition and nutrition and non-ruminants.

Keywords: Animal Nutrition. Bromatology. Handout.
Universidade Federal de Minas Gerais

Correspondência/Contato

Av. Antônio Carlos, 6627

Pampulha: 31270-901

BELO HORIZONTE - MG

revistadocenciadoensinosuperior@ufmg.br 


\section{INTRODUÇÃO}

A biodiversidade do cerrado brasileiro é elevada, porém geralmente menosprezada (KLINK; MACHADO, 2005). O número de plantas vasculares é superior àquele encontrado na maioria das regiões do mundo: plantas herbáceas, arbustivas, arbóreas e cipós somam mais de 7.000 espécies (MENDONÇA et al., 1998). Muitas dessas espécies possuem características peculiares, formas variadas, e constituem importantes fontes alternativas de alimentos, com grande potencial de utilização na alimentação animal.

Recentes estudos demonstram a utilização desses alimentos, coprodutos e subprodutos do cerrado na nutrição animal. Pessoa et al. (2009), trabalhando com digestibilidade dos nutrientes da casca de pequi, verificaram que tal alimento apresentase como uma possível alternativa para alimentação de peixes. Rufino et al. (2011), ao avaliarem o líquido ruminal de caprinos alimentados com torta de macaúba, verificaram que o uso desse coproduto não interfere negativamente na microbiota ruminal, podendo ser utilizado na alimentação de ruminantes.

A criação de herbário e de mostruário é uma importante ferramenta para visualizarmos de forma didática as potencialidades dos ecossistemas regionais. Assim, este trabalho teve como objetivo fazer um levantamento de alimentos nativos do cerrado utilizados na alimentação animal com o propósito de confeccionar um herbário e mostruário dos mesmos, cujos resultados auxiliariam em forma de material didático as disciplinas de Bromatologia, Nutrição de Ruminantes e Nutrição de Não Ruminantes.

Considerando ainda as interfaces de atuação da UFMG: ensino-pesquisa e extensão, os resultados obtidos neste projeto também poderão ser aplicados em projetos de extensão e pesquisa, indicando alimentos que poderão servir como alternativas regionais, fomentando o desenvolvimento agropecuário sustentável.

\section{MATERIAL E MÉTODOS}

O Projeto Especial de Graduação teve início em abril de 2007. Para confecção do herbário e do mostruário, primeiramente, foi realizado levantamento com produtores rurais de Montes Claros e de outras cidades da região sobre os tipos de criações animais existentes, tipos de alimentos utilizados no arraçoamento dos animais, bem como alimentos do cerrado utilizados na alimentação dos animais. 
Foram entrevistados 54 produtores rurais, destes, 44 eram criadores de bovinos e 10 eram criadores de ovinos e/ou caprinos. Nenhum dos produtores entrevistados utilizava alimentos alternativos do cerrado na alimentação do seu rebanho, entretanto, 19,51\% tinham informações sobre esses alimentos. A casca de pequi e a torta de macaúba foram citadas por $1,08 \%$ dos produtores como produtos utilizados em propriedades vizinhas.

Após o levantamento dos dados sobre os produtos do cerrado, iniciou-se a montagem do mostruário de alimentos. Para confecção desse mostruário foram realizadas análises bromatológicas dos materiais identificados pelo levantamento com o intuito de agregar um maior número de informações técnicas a eles. Após as análises bromatológicas prontas, os alimentos foram armazenados em potes plásticos e transparentes, tendo sua composição bromatológica etiquetada para facilitar a visualização. Além dos produtos nativos do cerrado, foram incluídos no mostruário produtos comerciais como farelo de milho, soja, minerais e vitaminas, entre outros.

Durante a execução do projeto também foram realizadas revisões sobre utilização de alimentos regionais na nutrição de ruminantes, procurando resgatar o conhecimento local e confrontá-lo com o conhecimento científico existente. Essas revisões foram utilizadas durante as aulas da disciplina de Bromatologia, Nutrição de Ruminantes, Nutrição de Não Ruminantes e serviram também de material para auxiliar na confecção de uma apostila teórico-prática de Bromatologia.

Por meio de pesquisa embasada em artigos, internet, livros de nutrição animal, conversas informais com acadêmicos, participação do orientador e demais docentes da universidade, foi possível identificar as necessidades por informações que não constavam da apostila teórica de Bromatologia confeccionada. Após essa etapa, a apostila teórica de Bromatologia foi reformulada, com intuito de melhorar o entendimento. Durante a execução desse projeto, levantou-se a necessidade de criação de uma apostila prática de Bromatologia, uma vez que a bibliografia disponível para os cursos de Zootecnia e Agronomia nesta área encontra-se pulverizada em vários livros-texto.

\section{RESULTADOS}

A confecção do mostruário e do herbário mostrou-se de suma importância, pois proporcionou ao aluno da graduação o conhecimento dos ingredientes disponíveis na região e suas potencialidades de utilização na alimentação animal. Permitindo, assim, recomendação segura de ingredientes para a alimentação animal, contribuindo também 
para despertar nos discentes a consciência da importância do desenvolvimento de uma agropecuária baseada na sustentabilidade e conhecer a realidade das populações locais.

Além de ser utilizado nas aulas práticas, o mostruário e o herbário foi importante para divulgação do potencial dos produtos do cerrado para a comunidade local. Esses trabalhos de divulgação foram feitos no programa Jovens Talentos e na comemoração dos 80 anos da UFMG, envolvendo estudantes do Ensino Fundamental e Primário respectivamente, ambos da rede pública municipal de Montes Claros, em parceria entre a prefeitura da cidade e o Instituto de Ciências Agrárias da UFMG.

A participação no programa Jovens Talentos e na comemoração dos 80 anos da UFMG objetivou despertar o interesse científico nesses alunos, promovendo maior interação escola-universidade. Foram realizadas visitas monitoradas, com a finalidade de mostrar o funcionamento do setor de Nutrição Animal do Departamento de Zootecnia - ICA/UFMG, enfatizando a utilização de produtos do cerrado na alimentação dos animais de interesse zootécnicos.

Após a realização de parte dessas atividades, percebemos que na região do Norte de Minas Gerais pouco se conhece do uso de produtos nativos para alimentação animal. Portanto, notamos a real importância desse trabalho no sentido de divulgar e incentivar a utilização de tais produtos e mostrar para os alunos e produtores rurais a relevância da utilização destes para sustentabilidade do cerrado, podendo ser uma forma econômica de se produzir.

Outra atividade realizada foi a atualização da apostila da disciplina de Bromatologia, com novos conceitos da nutrição animal e correções necessárias. Essa etapa foi de suma importância, pois surgia o interesse de publicar a obra em formato digital. Os assuntos tratados na apostila foram considerados componentes de um guia de préleitura dos livros indicados pela disciplina e foram utilizados como referência inicial de leitura.

Além da atualização da apostila teórica, foi feita uma nova apostila de Bromatologia prática, para facilitar o acompanhamento das aulas práticas pelos alunos, de modo que eles pudessem ter acesso ao roteiro das análises bromatológicas apresentadas na aula e anexos relevantes, melhorando a dinâmica da aula e o aprendizado dos alunos. Outro ponto a ser ressaltado é que a disponibilização da apostila teóricoprática de Bromatologia otimizou o tempo utilizado pelo professor na disciplina e o tempo de estudo dos alunos. 
Após o aprimoramento e atualização dos materiais da disciplina de Bromatologia, foi criada a disciplina Informática Aplicada à Zootecnia, na qual diversas planilhas, que abordavam temas como cálculo de rações, gerenciamento de rebanho, custos de produção, entre outros, foram desenvolvidas; com o intuito didático de auxiliar no aprendizado dos alunos, transformando teoria em prática. A disciplina Informática Aplicada à Zootecnia possibilitou aos alunos criar e gerenciar os próprios softwares, tornando-os mais preparados para o mercado de trabalho.

Embora este projeto envolva aspectos meramente acadêmicos, é importante ressaltar que em oportunidades futuras ele poderá ser continuado por pesquisas que envolvam o uso da informática na modelagem de sistemas biológicos, avaliação biológica de alimentos destinados ao arraçoamento animal e trabalhos de extensão rural visando à divulgação da potencialidade desses alimentos para a alimentação animal.

\section{CONCLUSÃO}

A confecção do mostruário e do herbário contribuiu para despertar nos discentes a consciência da importância de se desenvolver uma agropecuária baseada na sustentabilidade e de se conhecer a realidade das populações locais. Assim, a criação desse material didático chamou a atenção para as potencialidades dos ecossistemas regionais e a cultura das populações que historicamente vivem e convivem com os cerrados e as caatingas do semiárido brasileiro.

\section{REFERÊNCIAS}

KLINK, C. A.; MACHADO, R. A conservação do cerrado brasileiro. Megadiversidade, v. 1. n. 1, p. 147-155, jul. 2005. Disponível em: <http:// www.agencia.cnptia.embrapa.br/recursos/Texto_Adicional_conservacaolDxNOKMLsupY.pdf.>. Acesso em: 1 jan. 2007.

MENDONÇA, R. J. et al. Flora vascular do cerrado. In: SANO, S.; e ALMEIDA, S. (Ed.). Cerrado: ambiente e flora. Planaltina: Empresa Brasileira de Pesquisa Agropecuária, 1998. p. 288-556.

PESSOA, M. S. et al. Digestibilidade dos nutrientes da casca de pequi (Caryocar brasiliensis Camb.) para Tilápias do Nilo. In: ASSOCIAÇÃO BRASILEIRA DE ZOOTECNISTAS, 2009, Águas de Lindoia. Anais... Águas de Lindoia: Zootec, 2009. CD-ROM.

RUFINO, L. M. et al. Efeitos da inclusão de torta de macaúba sobre a população de protozoários ruminais de caprinos. Revista Brasileira de Zootecnia, v. 40, n. 4, p. 899-903, 2011. 